\title{
ANALISIS PERBEDAAN KINERJA KEUANGAN ANTARA BPD SYARIAH DAN BPD KONVENSIONAL DI JAWA MENGGUNAKAN METODE RGEC ${ }^{1}$
}

\author{
Novrina Atika Putri \\ Departemen Ekonomi Syariah - Fakultas Ekonomi dan Bisnis - Universitas Airlangga \\ Email: novrinatika@gmail.com \\ Siti Zulaikha \\ Departemen Ekonomi Syariah - Fakultas Ekonomi dan Bisnis - Universitas Airlangga \\ Email: iyun.zulaikha@gmail.com
}

\begin{abstract}
:
The RGEC approach is an assessment of the latest bank soundness that consists of risk profile, good corporate governance, earnings, capital, each of which is projected with the bank's financial performance. RGEC is able to identify problems early, solve problems more quickly, and implement better GCG and risk management so that it is resistant to crisis. This study aims to analyze whether there are differences between the level of health of conventional BPD and Islamic BPD in Java using the RGEC approach. This type of research is quantitative research. The sample in this study was selected by means of purposive sampling, based on predetermined criteria then obtained 4 conventional BPDs and 4 Islamic BPDs. The data analysis technique used in this study is the two different test averages (independent sample t-test). The results of this study prove that there are significant differences in the FDR and ROA variables between conventional BPD and Islamic BPD and there are no significant differences in the NPF, GCG, CAR variables.
\end{abstract}

Keywords: RGEC, Bank Healthy, NPF, FDR, GCG, ROA, CAR

\section{PENDAHULUAN}

Bank adalah lembaga keuangan yang kegiatan utamanya menghimpun dana dari masyarakat dan menyalurkan kembali dana tersebut ke masyarakat serta memberikan jasa bank lainnya (Kasmir, 2012). Jenis bank jika dilihat dari segi atau caranya dalam menentukan harga, baik harga jual maupun harga beli terbagi dalam dua kelompok, yaitu bank syariah dan bank konvensional (Kasmir, 2012). Bank Syariah sendiri adalah bank yang menjalankan segala sesuatunya seperti kegiatan usaha dan kegiatan operasionalnya berdasarkan prinsip syariah, seperti tidak adanya unsur bunga, maysir, gharar, riba dan lain-lain.
Dalam surat Al-Baqarah ayat 278-279 Allah SWT berfirman:

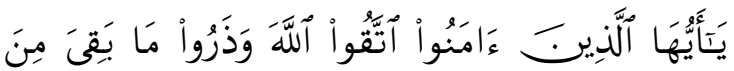

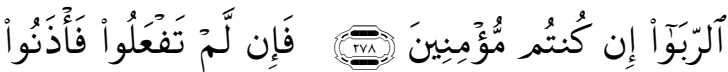

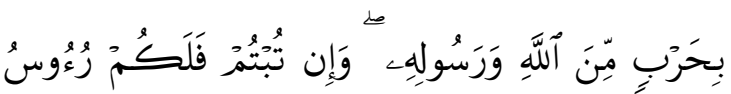

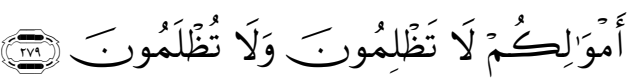
Ya ayyuha allatheena amanoo ittaqoo Allaha watharoo ma baqiya mina alrriba in kuntum mumineena (278) Fain lam tafAAaloo fathanoo biharbin mina Allahi warasoolihi wain tubtum falakum ruoosu amwalikum la tathlimoona wala tuthlamoona (279)

Artinya: Hai orang-orang yang beriman, bertakwalah kepada Allah dan tinggalkan sisa riba (yang belum dipungut) jika kamu

\footnotetext{
${ }^{1}$ Jurnal ini merupakan bagian dari skripsi Novrina Atika Putri, NIM: 04151 1433082, yang diuji pada tanggal 25 Juni 2019.
} 
Putri, et al/Jurnal Ekonomi Syariah Teori dan Terapan Vol. 6 No. 8 Agustus 2019: 1706-1717; ANALISIS PERBEDAAN KINERJA KEUANGAN ANTARA BPD SYARIAH DAN BPD KONVENSIONAL DI JAWA MENGGUNAKAN METODE RGEC

orang-orang yang beriman (278). Maka jika kamu tidak mengerjakan (meninggalkan sisa riba), maka ketahuilah, bahwa Allah dan Rasul-Nya akan memerangimu. Dan jika kamu bertaubat (dari pengambilan riba), maka bagimu pokok hartamu; kamu tidak menganiaya dan tidak (pula) dianiaya (279).

Surat Al-Baqarah ayat 278-279 menjelaskan tentang orang-orang yang memakan riba, bahwa orang-orang tersebut adalah orang-orang yang nantinya akan mendapatkan azab yang pedih di dunia dan akhirat. Ayat ini mempertegas bahwa Allah memerintahkan pada orang-orang yang beriman dan bertakwa untuk menjauhkan diri mereka dari praktik riba di kehidupan sehari-harinya (Kementerian Agama RI).

Seiring bertambahnya pelaku pasar dan beragamnya produk atau jasa layanannya, maka pengawasan perbankan lebih komprehensif dan efektif. Metode pengawasan secara efektif diterapkan agar mampu mendeteksi sedini mungkin risiko-risiko yang sedang dihadapi perbankan. Hasil penilaian resiko penetapan tingkat kesehatan bank dan hasil pemeriksaan tersebut akan dijadikan dasar dalam melakukan tindak lanjut pembinaan dalam rangka perbaikan kondisi perbankan (Daniswara, 2016).

Penilaian kesehatan bank telah mengalami beberapa perubahan sejak pertama kali diberlakukan pada tahun 1999 yaitu kebijakan CAMEL yang terdiri dari: Permodalan (capital), Kualitas Aset (Aset Quality), Manajemen (management), Rentabilitas (Earnings), dan terakhir Likuditas (Liquidity). Kelima aspek tersebut saling berkaitan dan mempengaruhi satu sama lain., kemudian mengalami perubahan menjadi CAMELS terdiri dari: Permodalan (capital), Kualitas Aset (Asset Quality), Manajemen (management), Rentabilitas (Earnings), Likuiditas (Liquidity), Sensivitas terhadap risiko pasar(Sensivity to Market Risk) dan kini Bank Indonesia telah menetapkan kebijakan yang dinilai lebih mampu untuk mengukur kesehatan bank yaitu RGEC terdiri dari: risk profile, good corporate governance, earnings, capital. Melalui RGEC, Bank Indonesia menginginkan agar bank mampu mengidentifikasi permasalahan secara dini, serta melakukan tindak lanjut perbaikan yang sesuai dan cepat, serta menerapkan Good Corporate Governance dan manajemen risiko yang diterapkan lebih baik sehingga bank lebih tahan dalam menghadapi krisis.

Bank Pembangunan Daerah (BPD) sebagai salah satu bank yang ada pada sistem perbankan nasional yang memiliki fungsi dan peran yang signifikan dalam konteks pembangunan ekonomi regional karena BPD mampu membuka jaringan pelayanan di daerah-daerah secara ekonomis yang tidak bisa dilakukan oleh bank swasta. Berdasarkan data dari Otoritas Jasa Keuangan (OJK) per 31 Desember 2013, terdapat 26 BPD yang 
Putri, et al/Jurnal Ekonomi Syariah Teori dan Terapan Vol. 6 No. 8 Agustus 2019: 1706-1717; ANALISIS PERBEDAAN KINERJA KEUANGAN ANTARA BPD SYARIAH DAN BPD KONVENSIONAL DI JAWA MENGGUNAKAN METODE RGEC

berdiri di Indonesia, dan terdapat 4 BPD yang berdiri di provinsi Jawa yaitu BPD Jawa Tengah, BPD Jawa Barat dan Banten, BPD Jawa Timur dan BPD DIY yang masing-masing mempunyai UUS.

Untuk mengetahui tingkat kinerja kevangan pada BPD konvensional dan BPD syariah dapat diukur melalui laporan keuangan yang dianalisis menggunakan alat ukur yaitu rasio keuangan. Rasio dapat menggambarkan suatu hubungan antara jumlah tertentu dengan jumlah yang lainnya. Rasio keuangan digunakan untuk membandingkan angka-angka yang ada dalam laporan keuangan dengan cara membagi suatu angka dengan angka lainnya. (Kasmir, 2010).

Rumusan Masalah1. Apakah terdapat perbedaan antara risk profile (NPF dan NPL) BPD konvensional dan BPD syariah di Jawa? 2. Apakah terdapat perbedaan antara risk profile (FDR dan LDR) BPD konvensional dan BPD syariah di Jawa? 3. Apakah terdapat perbedaan antara (GCG) BPD konvensional dan BPD syariah di jawa? 4. Apakah terdapat perbedaan antara earnings (ROA) BPD konvensional dan BPD syariah di Jawa? 5. Apakah terdapat perbedaan antara capital (CAR) BPD konvensional dan BPD syariah di Jawa?

\section{LANDASAN TEORI DAN PENGEMBANGAN HIPOTESIS}

Menurut Veithzal Rivai, dkk (2012) Kesehatan bank merupakan kepentingan semua pihak terkait, baik pemilik, manajemen bank, bank pemerintah (melalui Bank Indonesia) serta penguna jasa bank. Dengan diketahuinya kondisi dari suatu bank dapat digunakan untuk mengevaluasi kinerja bank dalam menerapkan prinsip kehati-hatian, kepatuhan terhadap ketentuan yang berlaku dan manajemen risiko. Perkembangan industri perbankan, terutama produk dan jasa yang semakin kompleks dan beragam akan meningkatkan eksposur risiko yang dihadapi oleh bank. Perubahan eksposur risiko bank dan penerapan manajemen risiko akan dapat mempengaruhi profil risiko bank yang selanjutnya akan berakibat pada kondisi bank secara keseluruhan.

Berdasarkan peraturan bank Indonesia No. 13/1/PBI/2011 dan SE BI No. 13/24/DPNP yang berlaku per Januari 2012 menggantikan penilaian kesehatan bank dengan netode CAMELS menjadi metode yang baru yaitu metode RGEC. Metode CAMELS tersebut sudah diberlakukan hampir delapan tahun sejak terbitnya $\mathrm{PBI}$ No. 6/10/PBI/2004 dan SE No. 6/23/DPNPA. Dengan terbitnya PBI dan SE terbaru ini, metode CAMELS dinyatakan tidak berlaku lagi, diganti dengan model baru yang mewajibkan BUK maupun BUS untuk melakukan penilaian sendiri (Self Assesment) Tingkat Kesehatan Bank dengan menggunakan pendekatan risiko RBBR (Risk Based Bank Rating) baik secara individual maupun secara konsolidasi.

Kinerja keuangan juga digunakan untuk melihat kinerja organisasi atau 
Putri, et al/Jurnal Ekonomi Syariah Teori dan Terapan Vol. 6 No. 8 Agustus 2019: 1706-1717; ANALISIS PERBEDAAN KINERJA KEUANGAN ANTARA BPD SYARIAH DAN BPD KONVENSIONAL DI JAWA MENGGUNAKAN METODE RGEC

perusahaan secara menyeluruh serta kontribusi dalam pencapaian tujuan perusahaan, dan digunakan juga sebagai dasar pembuatan strategi perusahaan dimasa yang akan datang, serta untuk memberi petunjuk dalam pembuatan keputusan kegiatan organisasi dan sebagai dasar penentuan kebijakan penanaman modal agar dapat meningkatkan efisiensi dan produktivitas perusahaan (Fahmi, 2011).

Menurut Kasmir (2015:104) rasio keuangan yaitu suatu kegiatan yang membandingkan angka-angka yang terdapat dalam laporan keuangandengan cara membagi satu angka dengan angka lainnya. Perbandingan dapat dilakukan anatara satu kmponen dengan komponen dalam satu laporan keuangan antar komponen yang ada di antara laporan keuangan kemudian angka yang diperbandingkan dapat berupa angka dalam satu periode maupun beberapa periode.

Rasio keuangan adalah hasil perhitungan dua macam data keuangan bank digunakan untuk menjelaskan hubungan antara kedua data tersebut dinyatakan secara numerik, baik dalam presentase atau kali. Hasil perhitungan rasio ini digunakan untuk menguji kinerja keuangan bank pada periode tertentu dan dapat digunakan sebagai tolak ukur untuk menilai tingkat kesehatan bank selama periode keuangan tersebut (Riyadi, 2006).
Dengan mengetahui rasio keuangan bank maka kita akan menilai kinerja dari setiap bank apakah bank tersebut telah bekerja secara efisien dan bagaimana tingkat kesehatan bank tersebut, serta upaya apa yang harus dilakukan agar bank tersebut dapat bekerja lebih efisisen dan lebih baik lagi. Kinerja keuangan menunjukkan kaitan yang cukup erat dengan penilaian mengenai sehat atau tidaknya suatu perusahaan. Jika kinerja suatu perusahaan memiliki kinerja yang baik maka baik pula tingkat kesehatannya.

$\mathrm{H}_{1}$ : Terdapat perbedaan dalam profil risiko (NPL dan NPF) antara BPD Islam dan BPD konvensional di Jawa.

$\mathrm{H}_{2}$ : Terdapat perbedaan dalam profil risiko ( FDR dan LDR) antara BPD Islam dan BPD konvensional di Jawa.

$\mathrm{H}_{3}$ : $\quad$ Terdapat perbedaan dalam GCG tadbir urus korporat yang baik antara BPD Islam dengan BPD konvensional di Jawa.

$\mathrm{H}_{4}$ : Terdapat perbedaan ROA pendapatan antara BPD Islam dan BPD konvensional di Jawa.

H5: Tidak ada perbedaan modal antara BPD Islam dan BPD konvensional di Jawa. 


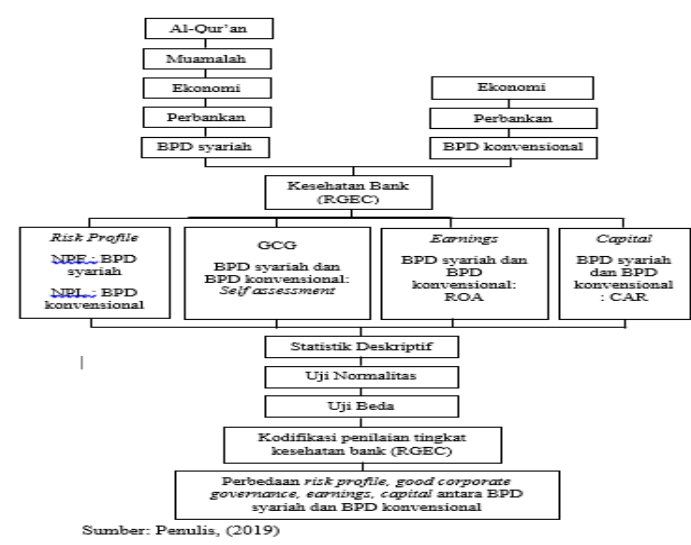

Gambar 1.

Kerangka Berpikir

\section{METODE PENELITIAN}

Pendekatan yang dilakukan dalam penelitian ini adalah pendekatan kuantitatif. Penelitian kuantitatif merupakan penelitian yang menekankan analisisnya pada data-data numerical (angka) yang diolah dengan metode statistic. Dengan metode kuantitatif akan diperoleh signifikan perbedaan kelompok atau signifikan hubungan antara variabel yang diteliti (Siregar,2015). Pendekatan kuantitatif digunakan karena penelitian ini dilakukan untuk menguji hipotesis dan membuktikan asumsi sebelumnya dengan menggunakan data terukur, sehingga dapat menghasilkan kesimpulan yang dapat dipertanggungjawabkan.

Pengertian non perfoming financing menurut Rahmania dan Wibowo (2015), NPF merupakan pembiayaan bermasalah dari nasabah kepada bank. Semakin tinggi NPF maka semakin menurunkan kinerja perbankan.

Pengertian finance to deposit ratio menurut Suwiknyo (2010), FDR merupakan rasio pembiayaan dana pihak ketiga yang diterima oleh bank. FDR adalah perbandingan yang berasal dari pembiayaan yang diberikan oleh bank dengan dana pihak ketiga yang berhasil dihimpun oleh bank. FDR suatau rasio keuangan yang menunjukkan kesehatan bank dalam memberikan pembiayaan.

Menurut Saharuddin (2015), good corporate governance ialah suatu sistem yang mampu mengontrol dan mengarahkan perusahaan secara keseluruhan yang ditetapkan baik secara internal maupun eksternal atas kebijakan manajemen masing-masing bank dengan tujuan untuk melindungi kepentingan para stakeholder.

ROA adalah rasio keuangan yang menggambarkan kemampuan bank dalam mengelola dana yang diinvestikan dalam keseluruhan aset yang akan menghasilkan keuntungan. ROA merupakan gambaran produktivitas bank dalam mengelola dana sehingga menghasilkan keuntungan (Suwiknyo, 2016).

Menurut Aini (2013), rasio kecukupan modal atau CAR berkaitan dengan penyediaan modal sendiri yang diperlukan untuk menutup risiko kerugian yang mungkin timbul dari penanaman dana dalam aktiva-aktiva produktif yang mengandung risiko, serta untuk pembiayaan penanaman dalam aktiva tetap dan investasi. CAR merupakan kecukupan modal dengan tujuan menunjukkan kemampuan bank dalam 
Putri, et al/Jurnal Ekonomi Syariah Teori dan Terapan Vol. 6 No. 8 Agustus 2019: 1706-1717; ANALISIS PERBEDAAN KINERJA KEUANGAN ANTARA BPD SYARIAH DAN BPD KONVENSIONAL DI JAWA MENGGUNAKAN METODE RGEC

mempertahankan modal yang mencukupi.

Populasi merupakan wilayah generalisasi yang terdiri dari objek atau subjek yang mempuyai kualitas dan karakteristik tertentu yang ditetapkan sendiri oleh peneliti untuk dipelajari dan kemudian dapat ditarik kesimpulannya. Dalam penelitian ini populasinya adalah seluruh BPD syariah dan BPD konvensional yang beroperasi di Indonesia. Jumlah BPD Se-Indonesia yang terdaftar pada 31 Desember 2018 adalah sebanyak 26 bank.

Siregar (2015) menyatakan sampel adalah suatu prosedur pengambilan data dimana hanya sebagian populasi saja yang diambil dan dipergunakan untuk menentukan sifat serta ciri yang dikehendaki dari suatu populasi. Kemudian metode penentuan sampel yang digunakan dalam penelitian ini adalah metode purposive sampling yang merupakan metode penetapan responden untuk dijadikan sampel berdasarkan kriteria tertentu.

Berdasarkan kriteria tersebut maka bank yang memenuhi kriteria adalah sebanyak 4 BPD konvensional dan 4 BPD syariah periode 2013-2017 yaitu BPD BJB konvensional, BPD Jateng konvensional, BPD Jatim konvensional, BPD DIY konvensional serta BPD BJB syariah, BPD Jateng syariah, BPD Jatim syariah, BPD DIY syariah.

Uji beda independent digunakan untuk mengetahui ada atau tidaknya perbedaan rata-rata antara dua kelompok sampel yang tidak berhubungan. Jika terdapat perbedaan, rata-rata manakah yang lebih tinggi. Syarat dari uji bedaindependent adalah data harus memenuhi asumsi normalitas. Uji maan-whitney-test merupakan uji statistik non parametric yang digunakan pada data ordinal ataupun data interval apabila data tersebut tidak terdistribusi normal. Sama halnya dengan uji $\dagger$ uji maan whitney-test juga dapat digunakan untuk menganalisis ada tidaknya perbedaan antara rata-rata dua data yang saling independent.

\section{HASIL DAN PEMBAHASAN}

Uji beda dua sampel yang dilakukan pada penelitian ini dengan proyeksi dari risk profile, good corporate governance, earnings, capital menggunakan metode RGEC yang bertujuan untuk mengetahui tingkat kesehatan bank BPD syariah dan BPD konvensional di Jawa serta untuk mengetahui seccara umum apakah rasio risk profile, good corporate governance, earnings, capital memiliki perbedaan yang signifikan atau tidak.

Uji beda dua sampel independent pada penelitian ini dilakukan menggunakan dua metode yang berbeda yaitu uji beda sample t-test untuk data yang terdistribusi normal dan uji beda man whitney untuk data yang tidak terdistribusi normal. Berikut ini adalah hasil dari uji beda dua sampel yang dilakukan menggunakan bantuan program 
computer untuk analisis statistika yaitu SPSS

20:

Tabel 1.

Uji NPL NPar Tests

Mann-Whitney Test

Ranks

\begin{tabular}{|c|c|c|c|c|}
\hline \multirow{2}{*}{ NPL } & Kelompok & N & $\begin{array}{c}\text { Mean } \\
\text { Rank }\end{array}$ & $\begin{array}{c}\text { Sum of } \\
\text { Ranks }\end{array}$ \\
\hline & $\begin{array}{c}\text { Konvensional } \\
\text { Syariah } \\
\text { Total }\end{array}$ & 20 & 23.13 & 462.50 \\
\cline { 1 - 1 } & & 17.88 & 357.50 \\
\hline
\end{tabular}

Test Statistics ${ }^{a}$

\begin{tabular}{|c|c|}
\hline & NPL \\
\hline Mann-Whitney U & 147.500 \\
Wilcoxon W & 357.500 \\
Z & -1.420 \\
Asymp. Sig. (2-tailed) & .156 \\
Exact Sig. [2*(1-tailed Sig.)] & $.157 \mathrm{~b}$ \\
\hline
\end{tabular}

Sumber: Hasil uji SPSS 20 (diolah)

Metode RGEC memperhitungkan risk profile utama yaitu risiko kredit, dan risiko likuiditas. Berdasarkan tabel 4.1 pada pada risk profile pertama yaitu risiko kredit dengan proyeksi rasio NPF atau NPL dianalisis dengan menggunakan uji beda dua sampel man-whitney dengan hasil tingkat signifikansi sebesar 0.156 atau $15,6 \%$. Hasil tersebut menunjukkan tingkat signifikansi lebih dari 0.05 yang berarti hipotesis awal ditolak yaitu menunjukkan tidak adanya perbedaan yang signifikan pada risiko kredit yang diproyeksikan dengan NPF atau NPL pada BPD syariah dan BPD konvensional. Teknik yang digunakan oleh BPD syariah dan BPD konvensional dalam mengurangi risiko kredit adalah sama (Greuning dan labal, 2011).
Tabel 2.

Uji LDR T-test

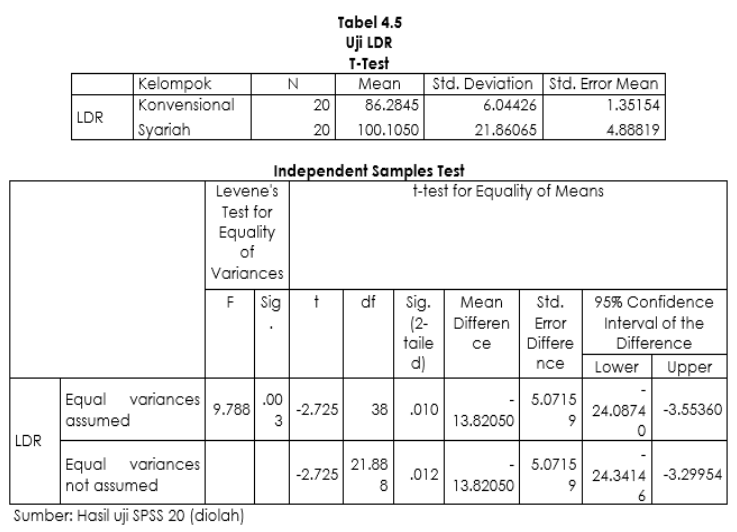

Risk profile yang kedua yaitu risiko likuiditas dengan proyeksi FDR atau LDR dianalisis menggunakan uji beda dua sample t-test menunjukkn hasil tingkat signifikan sebesar 0.012 atau $1,2 \%$. Hasil tersebut menunjukkan tingkat signifikansi kurang dari 0.05 yang berarti hipotesis awal diterima yaitu menunjukkan adanya perbedaan yang signifikan pada risiko likuiditas yang diproyeksikan dengan rasio FDR atau LDR pada BPD syariah dan BPD konvensional. Hal ini disebabkan karena jumlah dana yang diperlukan untuk membiayai pembiayaan menjadi semakin besar secara tomatis akan meningkatkan laba. Perolehan LDR BPD konvensional lebih baik dari BPD syariah karena sebagian besar DPK yang diperoleh merupakan dana milik pemerintah khususnya Pemda. Pendirian BPD adalah untuk mendorong pembangunan di daerah, dimana BPD diarahkan untuk menopang pembangunan infrastruktur, UMKM, pertanian, dan lain-lain kegiatan ekonomi dalam rangka pembangunan daerah. 
Putri, et al/Jurnal Ekonomi Syariah Teori dan Terapan Vol. 6 No. 8 Agustus 2019: 1706-1717; ANALISIS PERBEDAAN KINERJA KEUANGAN ANTARA BPD SYARIAH DAN BPD KONVENSIONAL DI JAWA MENGGUNAKAN METODE RGEC

Tabel 3.

Uji NPL NPar Tests

Mann-Whitney Test

\begin{tabular}{|c|c|c|c|c|}
\hline & Kelompok & $\mathrm{N}$ & $\begin{array}{c}\text { Mean } \\
\text { Rank }\end{array}$ & $\begin{array}{c}\text { Sum of } \\
\text { Ranks }\end{array}$ \\
\hline \multirow{4}{GC}{$\begin{array}{c}\text { Konvensio } \\
\text { nal }\end{array}$} & 20 & 22.68 & 453.50 \\
& $\begin{array}{c}\text { Syariah } \\
\text { Total }\end{array}$ & 20 & 18.33 & 366.50 \\
\hline
\end{tabular}

\begin{tabular}{|c|c|}
\multicolumn{2}{c}{ Test Statisticsa } \\
\hline & GCG \\
\hline Mann-Whitney U & 156.50 \\
& 0 \\
Wilcoxon W & 366.50 \\
0 \\
Z & -1.188 \\
Asymp. Sig. (2- \\
tailed) & .235 \\
Exact Sig. [2*(1- \\
tailed Sig.)] & $.242^{\mathrm{b}}$ \\
\hline
\end{tabular}

Sumber: Hasil ujiSPSS 20 (diolah)

Rasio ketiga yang terdapat dalam metode RGEC yaitu good corporate governance dianalisis menggunakan uji bedaman-whitney menunjukkn hasil tingkat signifikan sebesar 0.235 atau 2.3.5\%.

Hasil tersebut menunjukkan tingkat signifikansi lebih dari 0.05 yang berarti hipotesis awal ditolak yaitu menunjukkan tidak adanya perbedaan yang signifikan pada good corporate governance yang diproyeksikan dengan rasio GCG pada BPD syariah dan BPD konvensional. Untuk perumusan konsep GCG pada industri perbankan sebenarnya sama saja, baik dalam bank konvensional maupun bank syariah karena keduanya telah diatur oleh Bank Indonesia. Perumusan konsep GCG berawal dari sebuah visi dan misi di setiap perusahaan yang setelah itu disesuaikan dengan hukum dan peraturan yang berlaku dalam perusahaan tersebut,baik itu peraturan Bank Indonesia, surat edaran Bank Indonesia, dan segala peraturan yang berkaitan dengan dunia perbankan yang akhirnya terbentuk sebuah pedoman umum GCG. Secara umum, konsep GCG pada BPD konvensional dapat menjadi acuan teoritis pada BPD syariah, akan tetapi GCG tersebut harus terlebih dahulu distandarisasikan dengan nilai-nilai islam. Adanya dewan pengawas syariah pada BPD syariah yang menjadi pembeda antara struktur organisasi dalam BPD konvensional dan BPD syariah.

\section{Tabel 4}

\section{Uji ROA \\ NPar Tests Mann-Whitney Test}

Ranks

\begin{tabular}{|c|c|c|c|c|}
\hline & Kelompok & N & $\begin{array}{c}\text { Mean } \\
\text { Rank }\end{array}$ & $\begin{array}{c}\text { Sum of } \\
\text { Ranks }\end{array}$ \\
\hline \multirow{2}{*}{ ROA } & Konvensional & 20 & 24.93 & 498.50 \\
& $\begin{array}{c}\text { Syariah } \\
\text { Total }\end{array}$ & 20 & 16.08 & 321.50 \\
& 40 & & \\
\hline
\end{tabular}

Test Statisticsa

\begin{tabular}{|l|r|}
\hline & \multicolumn{1}{|c|}{ ROA } \\
\hline Mann-Whitney U & 111.500 \\
Wilcoxon W & 321.500 \\
Z & -2.394 \\
Asymp. Sig. (2-tailed) & .017 \\
Exact Sig. [2*(1-tailed Sig.)] & $.015 \mathrm{~b}$ \\
\hline
\end{tabular}

Sumber: Hasil uji SPSS 20 (diolah)

Rasio keempat yang terdapat dalam metode RGEC yaitu return on assets dianalisis menggunakan uji beda man-whitney menunjukkn hasil tingkat signifikan sebesar 0.17 atau 1,7\%. Hasil tersebut menunjukkan tingkat signifikansi kurang dari 0.05 yang berarti hipotesis awal diterima yaitu menunjukkan adanya 
Putri, et al/Jurnal Ekonomi Syariah Teori dan Terapan Vol. 6 No. 8 Agustus 2019: 1706-1717; ANALISIS PERBEDAAN KINERJA KEUANGAN ANTARA BPD SYARIAH DAN BPD KONVENSIONAL DI JAWA MENGGUNAKAN METODE RGEC

perbedaan yang signifikan pada return on assets yang diproyeksikan dengan rasio ROA pada BPD syariah dan BPD konvensional. Mengukur tingkat efisiensi usaha dan profitabilitas yang dicapai oleh BPD syariah dan BPD konvensional pada periode 2013-2017 telah dibuktikan bahwa ada perbedaan antara keduanya, hal ini dikarenakan adanya perbedaan tingkat perolehan laba yan didapat oleh BPD syariah dan BPD konvensional. BPD konvensional memiliki predikat yang sangat sehat karena didalam pasal 2 Keputusan Menteri Dalam Negeri (Kepmendagri) Nomor 62 tahun 1999 tentang pedoman organisasi dan tata kerja bank pembangunan daerah disebutkan bahwa BPD mempunyai tugas pokok sebagai pemegang kas daerah dan menyimpan vang daerah oleh sebab itu BPD konvensional mempunyai asset yang lebih tinggi. Namun BPD syariah tetap dalam batas normal yang telah ditentukan dalam surat edaran Bank Indonesia No. 13/24/DPNP/2011 kriteria dalam penetapan peringkat ROA dan sehat dan dapat mengimbangi BPD konvensional.

\section{Tabel 5. \\ Uji CAR \\ NPar Tests \\ Mann-Whitney Test}

\begin{tabular}{|c|c|}
\hline Mann-Whitney U & 153.000 \\
Wilcoxon W & 363.000 \\
Z & -1.271 \\
Asymp. Sig. (2-tailed) & .204 \\
Exact Sig. [2*(1-tailed Sig.)] & $.211^{\mathrm{b}}$ \\
\hline
\end{tabular}

Sumber: Hasil uji SPSS 20 (diolah)

Rasio kelima yang terdapat dalam metode RGEC yaitu capital adequacy ratio dianalisis menggunakan uji bedaman-whitney menunjukkn hasil tingkat signifikan sebesar 0.204 atau $20.4 \%$. Hasil tersebut menunjukkan tingkat signifikansi lebih dari 0.05 yang berarti hipotesis awal ditolak yaitu menunjukkan tidak adanya perbedaan yang signifikan pada capital adequacy ratio yang diproyeksikan dengan rasio CAR pada BPD syariah dan BPD konvensional. Menurut peraturan Bank Indonesia no. 151/12/PBI/1013 tentang adanya kewajiban penyediaan modal minimum menurut resiko masing-masing bank yang telah ditentukan oleh Bank Indonesia menjadi salah satu faktor tidak adanya perbedaan CAR antara BPD syariah dan BPD konvensional. Hal ini dapat dipahami karena bank diharuskan memenuhi kecukupan modalnya sebagaimana ditentukan oleh ketentuan Bank Indonesia tersebut. Ketentuan mengenai batas batas minimum CAR tersebut dari waktu ke waktu dapat berubah-ubah dan saat ini ketentuan dari Bank Indonesia menyatakan penyediaan CAR minimal Ranks

\begin{tabular}{|c|c|c|c|c|}
\hline & Kelompok & $\mathrm{N}$ & Mean Rank & Sum of Ranks alah 8\%. Jika rasio kecukupan modal \\
\hline \multirow{3}{*}{ CAR } & Konvensional & 20 & 22.85 & 457.00 adal \\
& Syariah & 20 & 18.15 & 363.00 semqkin besar maka tingkat keuntungan \\
& Total & 40 & & bank akan semakin besar dan meningkat.
\end{tabular}

Test Statistics ${ }^{a}$ CAR 


\section{SIMPULAN}

\section{Simpulan}

1. Risk profile pertama yaitu rasio kredit yang terdapat dalam metode RGEC diproyeksikan dengan rasio NPF dan NPL menunjukkan tidak adanya perbedaan yang signifikan antara rasio NPF BPD syariah dan rasio NPL BPD konvensional.

2. Risk profile kedua yaitu rasio likuiditas yang terdapat dalam metode RGEC diproyeksikan dengan rasio FDR dan LDR menunjukkan adanya perbedaan yang signifikan antara rasio FDR BPD syariah dan rasio LDR BPD konvensional.

3. Faktor self assessment yang terdapat dalam metode RGEC diproyeksikan dengan GCG menunjukkan tidak adanya perbedaan yang signifikan antara GCG BPD syariah dan GCG BPD konvensional.

4. Faktor rentabilitas yang terdapat dalam metode RGEC diproyeksikan dengan rasio ROA menunjukkan adanya perbedaan yang signifikan antara rasio ROA BPD syariah dan rasio ROA BPD konvensional

5. Faktor permodalan yang terdapat dalam metode RGEC diproyeksikan dengan rasio CAR menunjukkan tidak adanya perbedaan yang signifikan antara rasio CAR BPD syariah dan rasio CAR BPD konvensional.

\section{Keterbatasan Penelitian}

Berdasarkan hasil analisis yang telah dilakukan, peneliti memiliki beberapa keterbatasan dalam penelitian ini, yaitu:
1. Sampel BPD syariah dan BPD konvensional dalam penelitian ini hanya terdiri dari 4 BPS syariah dan 4 BPD konvensional dikarenakan tidak semua BPD syariah mempublikasikan laporan kevangan selama lima tahun berturut-turut sehingga untuk jumlah BPD konvensional mengikuti jumlah BPD syariah yang ada dan hanya mengambil sampel di Jawa.

\section{Saran}

1. Bagi BPD syariah

Secara umum, kinerja BPD syariah berimbang dengan BPD konvensional. Akan tetapi terdapat satu rasio BPD syariah yang mendapatkan predikat kurang sehat yaitu FDR. Untuk memperbaiki rasio FDR BPD syariah harus melakukan cara dengan menekan penyaluran dana pembiayaan dan lebih meningkatkan untuk pengumpulan DPK. BPD syariah diharapkan melakukan peningkatan atas kinerjanya pada masing-masing rasio keuangannya yaitu NPF, FDR, GCG, ROA dan CAR agar BPD syariah dapat terus bersaing didalam industri perbankan, serta terus mendapatkan kepercayan dari masyarakat sebagai bank dengan predikat yang sangat sehat serta siap dalam menghadapi risiko-risiko mendatang yang mungkin akan terjadi.

2. Bagi BPD konvensional,

BPD konvensional diharapkan dapat terus menjaga kestabilan dan lebih meningkatkan kinerjanya 
Putri, et al/Jurnal Ekonomi Syariah Teori dan Terapan Vol. 6 No. 8 Agustus 2019: 1706-1717; ANALISIS PERBEDAAN KINERJA KEUANGAN ANTARA BPD SYARIAH DAN BPD KONVENSIONAL DI JAWA MENGGUNAKAN METODE RGEC

terhadap masing-masing rasio kevangan seperti NPL, LDR, GCG, ROA, CAR dan selalu mentaati peraturan kodifikasi tingkat kesehatan bank yang telah diatur oleh $\mathrm{BI}$ dengan menggunakan metode RGEC. Menjaga kinerja masing-masing rasio agar dapat membuat perusahaan semakin berkembang dan selalu mendapatkan kepercayaan dari masyarakat khususnya bagi nasabah yang telah menggunakan jasa dan produk yang telah ditawarkan oleh BPD konvensional.

3. Bagi Peneliti Selanjutnya,

Pada penelitian ini peneliti hanya menggunakan lima rasio dalam hal membandingkan tingkat kesehatan BPD syariah dan BPD konvensional maka diharapkan peneliti selanjutnya dapat menambah rasio-rasio lainnya seperti rasio ROE yang merupakan bagian dari faktor rentabilitas, rasio ini juga penting karena untuk mengetahui seberapa seberapa efisien sebuah perusahaab dalam menggunakan vang yang didapat dari hasil investasi sang investor, hal ini penting karena salah satu pokok penting dari hasil akhir ROE adalah untuk mengetahui hasil laba bersih. Rasio NIM juga tak kalah penting digunakan untuk mengetahui manajemen bank dalam hal terutama pengelolaan aktiva produktif sehingga bisa menghasilkan laba bersih, rasio ini sangat penting dalam pengelolaan bank agar dapat meminimalisir masalah yang ada.

\section{DAFTAR PUSTAKA}

Daniswara, Fitria dan Nurmadi. 2016. Analisis Perbandingan Kinerja Kevangan Berdasarkan RGEC pada BUK dan BUS periode 2011-2014. GEMA， THN XXX/51/Februari-Juli 2016.

Kasmir. 2012. Analisis Laporan Kevangan. Jakarta: PT. Bumi Aksara.

Kasmir. 2012. Dasar-dasar Perbankan. Edisis Revisi. Jakarta: PT. Grafindo Persada.

Kasmir. 2012. Manajemen Perbankan. Edisi Revisi II. Jakarta: Rajawali Pers.

Marwanto. 2011. Analisis Komparatif Tingkat Kesehatan Bank Umum Syariah dan Bank Umum Konvensional dengan Metode RGEC periode 2012-2013. Jurnal Ekonomi.

Otoritas Jasa Keuagan No.10/SEOJK. 03/2014. Tentang Faktor PenilaianSelf Assessment GCG BUS/UUS(www.ojk.go.id). Diakses tanggal 13 Mei 2019.

Rifai. 2008. Islamic Financial Management. Jakarta: PT. Raja Grafindo Persada.

Siregar, Sofyan. 2015. Metode Penelitian Kuantitatif: Dilengkapi Perbandingan Perhitungan Manual \& SPSS. Jakarta: Kencana.

Sugari. 2015. Analisis Perbandingan Tingkat Kesehatan Bank Syariah dan Konvensional dengan 
Putri, et al/Jurnal Ekonomi Syariah Teori dan Terapan Vol. 6 No. 8 Agustus 2019: 1706-1717; ANALISIS PERBEDAAN KINERJA KEUANGAN ANTARA BPD SYARIAH DAN BPD KONVENSIONAL DI JAWA MENGGUNAKAN METODE RGEC

menggunakan Metode RGEC.

Fakultas Ekonomi dan Bisnis Universitas Jenderal Soedirman.
Sulistianingsih, H \& Maivalinda. 2018. Analisis Perbandingan Tingkat Kesehatan Bank Konvensional dan

Sugiono. 2007. Metode Penelitian

Kuantitatif Kualitatif dan R\&D.

Bandung: Alfabeta. 